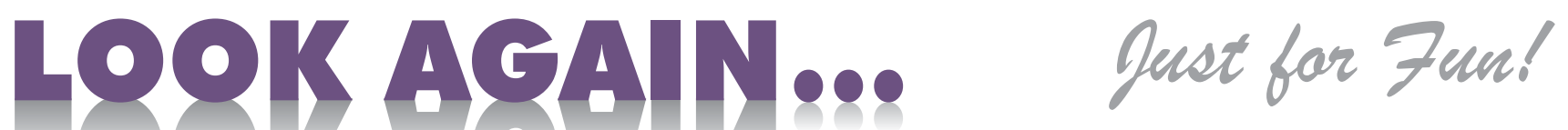

See if you can find the 8 differences

in each set of images.

On the beach at night, alone

A composite of three scanning electron microscope (SEM) images of a carbonized silicon nanowire array taken at different focal lengths. Utilizing the NovelX mySEM low-voltage imaging system, near- and farrange images were taken with standard backscatter collection while the middle-range image was taken using the Topo mode in order to capture the relief of the silicon "dunes." The three images were combined and colorized in photoshop. This scene takes its name from the Walt Whitman poem which describes the interconnected nature of the Universe, and the "vast similitude that interlocks all." While we work on the nanoscale, our efforts have an impact on the way humans interact with the world on the macroscale. Likewise, we find reflections of our macro world form in the shapes and forms of the nano one.

John Alper, University of California-Berkeley, USA

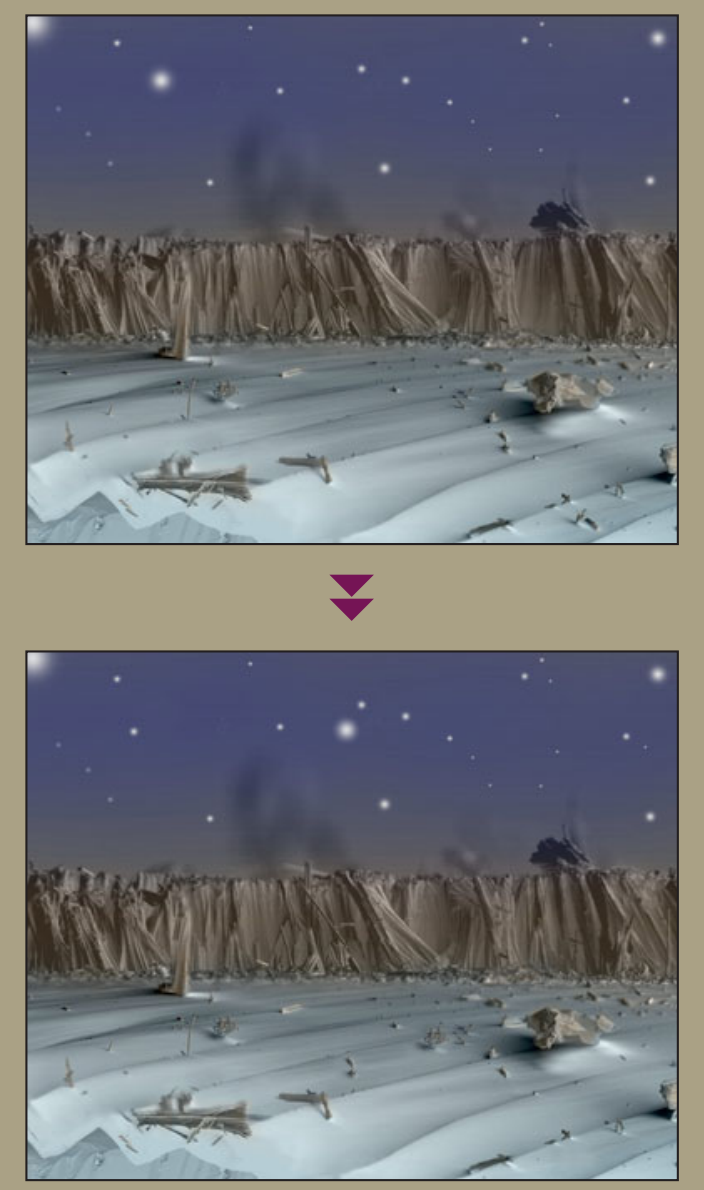

The answers will be in the October 2014 issue.

\section{Dark side of the blue moon}

Optical micrograph of a mesoporous thin film of tin-oxide nanoparticles. The film was prepared by spin casting a solution of the nanoparticles and a surfactant (Pluronic F-127) in THF (tetrahydrofuran) at $5000 \mathrm{rpm}$ for $1 \mathrm{~min}$, followed by annealing at $400^{\circ} \mathrm{C}$ for $30 \mathrm{~min}$. The nanoparticles are $\sim 2 \mathrm{~nm}$ in diameter, while the largest craters in the micrograph are $\sim 40-50 \mu \mathrm{m}$ across. Image dimensions are 720-540 $\mu \mathrm{m}$.

Lena Trotochaud, University of Oregon, USA
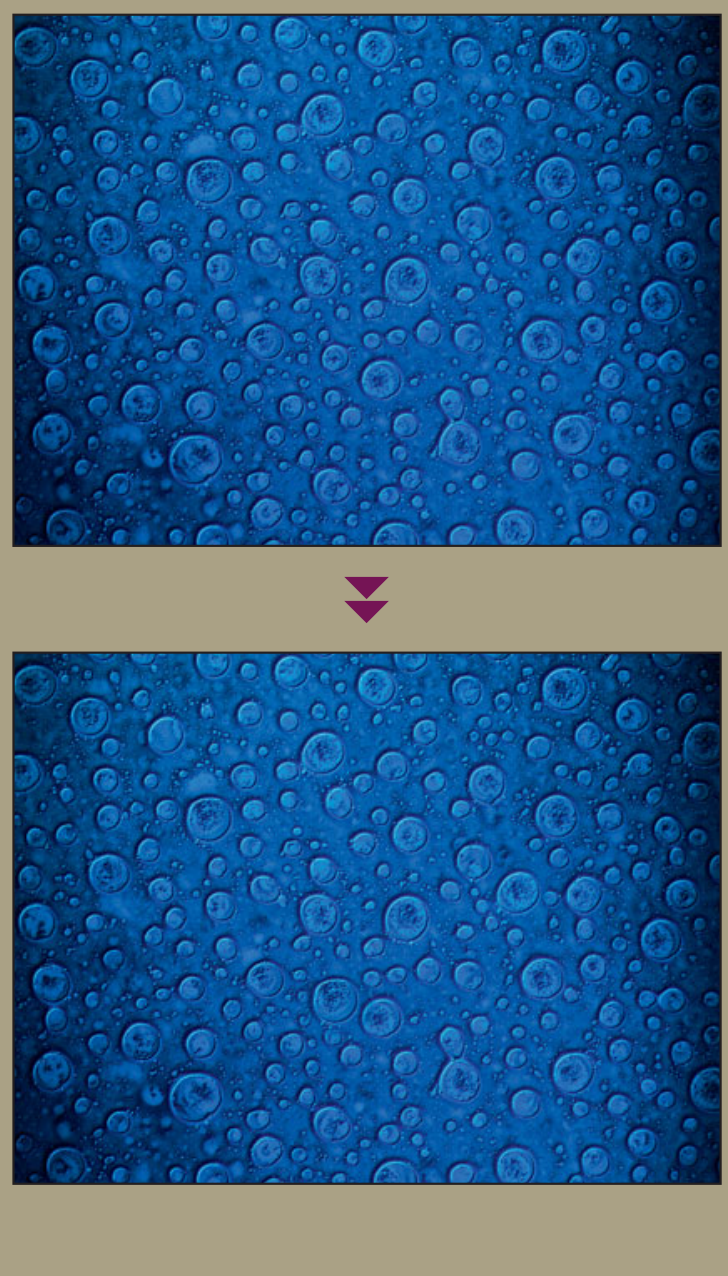

June 2014 answer key
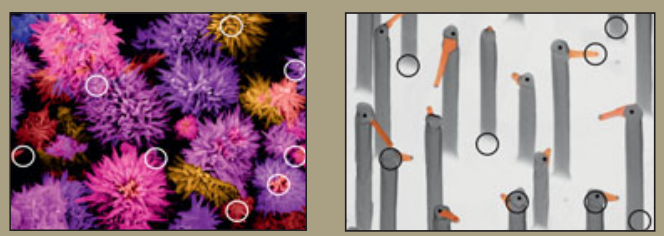